\title{
Variaciones de la acidez durante la incubación de las muestras en pruebas de demanda biológica de oxígeno
}

\author{
Jorge Alonso Cárdenas-León*, Ángela María Wilches-Flórez, Cindy Viviana Vanegas-Castillo
}

Facultad de Medio Ambiente y Recursos Naturales, Universidad Distrital Francisco José de Caldas, Bogotá, Colombia

\begin{abstract}
Resumen
En este trabajo se estudiaron las relaciones existentes entre la demanda biológica de oxígeno (DBO) y las variaciones de la acidez producidas durante el proceso de metabolización aeróbica de las aguas residuales domésticas. En una primera fase del proyecto se utilizaron soluciones patrón de glucosa y ácido glutámico y, en una segunda, muestras provenientes de la corriente influente de la Planta de Tratamiento de Aguas Residuales El Salitre, de Bogotá, Colombia. Se utilizaron botellas comerciales de color ámbar y $500 \mathrm{ml}$ de capacidad nominal para incubar las muestras; para la captura del bióxido de carbono generado por la metabolización aeróbica de la materia orgánica en la fase acuosa se empleó una solución tampón concentrada; posteriormente, se determinó la cantidad de $\mathrm{CO}_{2}$ generado durante la incubación de las muestras mediante titulación con una base fuerte. Se encontró que la DBO de las aguas residuales domésticas podía medirse cuantificando la acidez durante el metabolismo de la materia orgánica contenida con ventajas comparativas frente al método estándar de incubación durante cinco días. (C) 2017. Acad. Colomb. Cienc. Ex. Fis. Nat.
\end{abstract}

Palabras clave: Demanda biológica de oxígeno; Aguas residuales domésticas; Calidad de aguas; Análisis de aguas; Acidez; Demanda biológica de oxígeno.

\section{Variations of acidity during incubation of samples in biological oxygen demand tests}

\begin{abstract}
We studied the relationship between biological oxygen demand (BOD) and changes in acidity produced during aerobic metabolism of domestic wastewater. In a first phase of the project we worked with standard glucose-glutamic acid solutions, and in the second one, with samples from the influent stream of El Salitre Wastewater Treatment Plant in Bogotá, Colombia. We used commercial amber bottles with a sample incubating nominal capacity of $500 \mathrm{ml}$; we captured the carbon dioxide generated by aerobic metabolism of the organic matter in the aqueous phase using a concentrated buffer, and, subsequently, we determined the amount of $\mathrm{CO}_{2}$ generated during sample incubation by titration with a strong base. We found that the BOD of domestic wastewater can be measured by quantifying the acidity produced during the metabolism of organic matter contents, with comparative advantages as compared to the standard method of five days incubation. (C) 2017. Acad. Colomb. Cienc. Ex. Fis. Nat.
\end{abstract}

Key words: Biological oxygen demand; Domestic wastewater; Water quality; Water analysis; Acidity; Biological oxygen demand.

\section{Introducción}

La demanda biológica de oxígeno es una estimación semicuantitativa de los requerimientos de oxígeno que tienen las aguas residuales domésticas. Esta prueba se utiliza frecuentemente como criterio de calidad de vertimientos domésticos e industriales, así como para medir la eficiencia de los sistemas de remoción de carga orgánica, en las plantas de tratamiento de aguas residuales, (Eaton, Clesceri, Rice, Greenberg, 2005; Dogan, Sengorur, Koklu, 2009).

Existen básicamente dos métodos estándar para medir la DBO, el método de incubación a cinco días, y el método respirométrico, (Eaton, et al., 2005). El primero, mide la carga orgánica de las muestras, en función de la cantidad de oxígeno requerido para su oxidación biológica, por parte de microoorganismos biodegradadores, en cinco días, bajo condiciones cuidadosamente controladas ( $\mathbf{L i}$, et al., 2016) y, el segundo, en función del descenso de la presión causado por el consumo de oxígeno de la muestra, en un sistema $\mathrm{x}$ cerrado. Existen también otros métodos que han venido desarrollándose durante los últimos veinte años (Calderon, 2007) que apuntan fundamentalmente a tres objetivos. El primero, agilizar el tiempo de duración de los análisis, que en el método tradicional es de cinco días; el segundo, mejorar sustancialmente la reproducibilidad de las mediciones y, el tercero, simplificar el procedimiento de medición y las áreas de trabajo (Jouanneau, et al., 2014).

\footnotetext{
*Correspondencia:

Jorge Alonso Cárdenas-León, fluoreciencia@udistrital.edu.co

Recibido: 14 de julio de 2016

Aceptado: 06 de marzo de 2017
} 
Los avances de la investigación en este campo apuntan hacia el desarrollo de metodologías de análisis basadas en bio-sensores, que detectan la bio-luminiscencia producida por la utilización de una fuente de carbono, en el uso de celdas de combustible microbiano que generan una corriente eléctrica proporcional a la metabolización microbiana y en el uso de bio-sensores electroquímicos que determinan la actividad metabólica del sistema, mediante la medición del potencial redox de un mediador o intermediario que se adiciona al sistema, generalmente, el hexacianoferrato de potasio III, $\mathrm{K}_{3} \mathrm{Fe}(\mathrm{CN})_{6}$, ( Li, et al., 2016; Liu, et al., 2016).

En este estudio se explora la posibilidad de encontrar una correlación entre la DBO de una muestra de agua residual doméstica y su generación de bióxido de carbono, durante el proceso de incubación, con el propósito de aportar en el mejoramiento de la reproducibilidad de las mediciones y de la simplificación del procedimiento y de las áreas de trabajo.

El estudio utiliza botellas comerciales de color ámbar y $500 \mathrm{ml}$ de capacidad nominal para incubar las muestras; captura el bióxido de carbono generado por la metabolización aeróbica de la materia orgánica, en la fase acuosa, mediante un buffer concentrado $\mathrm{y}$, determina posteriormente por titulación con una base fuerte, la cantidad de $\mathrm{CO}_{2}$ generado durante la incubación de las muestras.

\section{Materiales y metodos}

Reactivos. Los reactivos se prepararon según metodología descrita en Standard Methods for examination of water and wastewater' (Eaton, et al., 2005).

Procedimientos. Todas las mediciones de oxígeno disuelto realizadas en éste estudio, fueron hechas por volumetría, según el método 4500-O C, Azide Modification, del Standar Methods for Examination of Water and Wastewate'.

Todas las mediciones de acidez realizadas en este estudio, fueron hechas por titulación de una alícuota de $100 \mathrm{ml}$ de muestra, blanco o patrón, con solución estándar de $\mathrm{NaOH}$ $0,025 \mathrm{~N}$, en presencia de fenolftaleína.

El estudio de las relaciones existentes entre la DBO de una muestra de agua residual doméstica y la correspondiente acidez producida durante el proceso de incubación de las muestras, se realizó en dos etapas. En una primera etapa se observó el comportamiento entre estas dos variables, utilizando como muestras de trabajo, soluciones patrón de glucosa-glutámico. En una segunda etapa, se utilizaron muestras de agua residual doméstica (ARD), provenientes del influente de la Planta de Tratamiento de Aguas Residuales El Salitre, facilitadas por la Empresa de Acueducto y Alcantarillado de Bogotá, Colombia, durante el año 2013.

Relaciones acidez/DBO en soluciones patrón de glucosa-glutámico. En esta primera etapa se utilizaron como muestras de análisis, soluciones patrón de glucosaglutámico, por la ventaja que ofrece para el estudio de las variables en cuestión, el trabajo sobre muestras con valor de DBO perfectamente conocido.
En este sentido, se pesaron $450 \mathrm{mg}$ de glucosa y 450 mg de ácido glutámico, anhidros y se disolvieron con agua destilada hasta un volumen total de $1000 \mathrm{ml}$. La DBO teórica de esta solución stock es de $600 \mathrm{mg} \mathrm{O} / 1$ (Eaton, et al., 2005). A partir de dicha solución se prepararon, 500 $\mathrm{ml}$ de cada una las soluciones patrón, abajo indicadas, con el objeto de observar la acidificación producida durante la incubación, a diferentes rangos de concentración:

Serie rango bajo: 20, 40, 60, 80 y $100 \mathrm{mg} \mathrm{O}_{2} / 1$

Serie rango medio: 40, 80, 120, 160 y $200 \mathrm{mg} \mathrm{O}_{2} / 1$

Serie rango alto: 100, 200, 300, 400 y $500 \mathrm{mg} \mathrm{O}_{2} / 1$

Para los ensayos de rango bajo de concentración, se utilizó $1,0 \mathrm{ml}$ de solución buffer concentrada, por cada 500 $\mathrm{ml}$ de muestra o blanco. Para los ensayos de rango medio, 2,0 $\mathrm{ml}$ y para los ensayos de rango alto, 3,0 $\mathrm{ml}$. Todas las muestras y blancos se inocularon con $0,5 \mathrm{ml}$ del efluente de una planta de tratamiento de aguas residuales, por cada 500 $\mathrm{ml}$ de muestra o blanco.

En este estudio, las muestras se incubaron en botellas comerciales de color ámbar y $500 \mathrm{ml}$ de capacidad nominal, provistas de tapa y contratapa plásticas, que garantizan un cierre hermético.

Dentro de cada ensayo, cada muestra se incubó por duplicado, en alícuotas de $200 \mathrm{ml}$, para rangos de concentración bajo y medio y, en alícuotas de $100 \mathrm{ml}$, para rango alto de concentración. A cada una de las botellas se le incorporó un agitador magnético de aproximadamente $3,0 \mathrm{~cm}$ de longitud $\mathrm{y}$, posteriormente, se tapó cada botella herméticamente.

En cada serie de ensayos, las botellas se colocaron sobre la plancha de agitación magnética de un equipo Oxitop ${ }^{\circledR}$ IS $12 \mathrm{y}$, posteriormente, se incubaron a $20 \pm 1^{\circ} \mathrm{C}$ durante cinco días, con una variación de más o menos 4 horas.

Luego de los cinco días de incubación, se retiraron las muestras de la incubadora y se tituló una alícuota de $100 \mathrm{ml}$ de cada una de las muestras, con $\mathrm{NaOH}$ estándar $0,025 \mathrm{~N}$, en presencia de fenolftaleína. Las titulaciones se realizaron con bureta digital y apoyo de agitación magnética, tomando como punto final de la titulación, la permanencia en la mezcla reaccionante, de un tinte rosado, durante más de 10 segundos. Por último, se realizaron los cálculos de las titulaciones y se expresó la acidez obtenida, como miligramos de carbonato de calcio por litro de muestra. De acuerdo con la hipótesis de trabajo, muestras con altos valores de DBO, deberían corresponder con altos valores de acidez y viceversa.

Relaciones acidez/DBO en aguas residuales domésticas. El estudio de las relaciones entre la acidez y la DBO, en aguas residuales domésticas, se realizó sobre muestras provenientes del influente de la Planta de Tratamiento de Aguas Residuales El Salitre, facilitadas por la Empresa de Acueducto y Alcantarillado de Bogotá, durante el 2013.

El procedimiento consistió en recoger un galón de muestra y trasladarla al Laboratorio de Aguas de la Facultad del Medio Ambiente y Recursos Naturales, de la Universidad Distrital Francisco José de Caldas, e iniciar los ensayos, antes de transcurridas cuatro horas, después del muestreo. 
Ya en el laboratorio, la muestra se homogenizó por agitación mecánica durante varios minutos y luego se filtró sobre un lecho de algodón.

La muestra así tratada se dividió en dos porciones. Una de ellas se utilizó para la medición de la $\mathrm{DBO}_{5}$, por el método estándar de incubación a cinco días, (Eaton, et al., 2005) y, la otra, se tomó como solución stock, para preparar a partir de ella, por dilución con agua de dilución, una serie de soluciones patrón, cuya concentración se calculó posteriormente, a partir del resultado experimental obtenido para la $\mathrm{DBO}_{5}$, por el método estándar de incubación a cinco días.

Cada dilución de la muestra, de agua residual doméstica, se incubó por duplicado en botellas comerciales de color ámbar y $500 \mathrm{ml}$ de capacidad nominal, provistas de cierre hermético, de manera semejante a como se procedió con las soluciones patrón de glucosa y ácido glutámico.

\section{Resultados y discusión}

Relaciones acidez vs DBO en muestras de glucosaglutámico, rango bajo. Los resultados obtenidos para el estudio de las relaciones acidez vs DBO en muestras artificiales de glucosa y ácido glutámico, para rangos bajo y medio de concentración, se muestran en las figuras 1 y 2 , respectivamente. Estos resultados se refieren a la acidez de las muestras, medida después del periodo de incubación de cinco días. En esta primera etapa, no se midió la acidez inicial de las muestras.

Nótese que en ambas gráficas, se obtiene como resultado, una inequívoca relación lineal entre la DBO de la muestra y su acidez, después de la incubación. Así lo indica el coeficiente de correlación lineal, superior, en ambos casos, al $95 \%$. Ensayos semejantes, realizados en condiciones semejantes, arrojan los mismos resultados. Sin embargo, las variables de la recta, pendiente y corte con el eje ' $\mathrm{Y}$ ', cambian cuando se cambia la cantidad de buffer aplicado.

Las figuras 1 y 2 , sugieren que es posible medir la DBO de una muestra, no solo en función del consumo de oxígeno, durante la incubación de las muestras, sino también, en función de la acidez que genera, la metabolización aerobia de la materia orgánica contenida en la muestra. No obstante, estos ensayos, por sí solos, no son contundentes, por cuanto se debe tener en cuenta que estas muestras, contienen cantidades proporcionales de ácido glutámico. Es decir, que la pendiente de las líneas rectas, en estas figuras, podría darse, no solo por la acidez producida en la metabolización de la materia orgánica, sino también, por la concentración creciente del ácido glutámico, en las muestras. En síntesis, la tendencia es lineal pero el resultado no es concluyente. Es por esto que es necesario, trabajar en una segunda etapa, con muestras reales de agua residual doméstica.

Relaciones acidez vs DBO en agua residual doméstica. Los resultados obtenidos para el estudio de las relaciones acidez vs DBO en muestras de agua residual doméstica, se presentan separadamente en cuatro ensayos diferentes. En los dos primeros, se presentan también los resultados

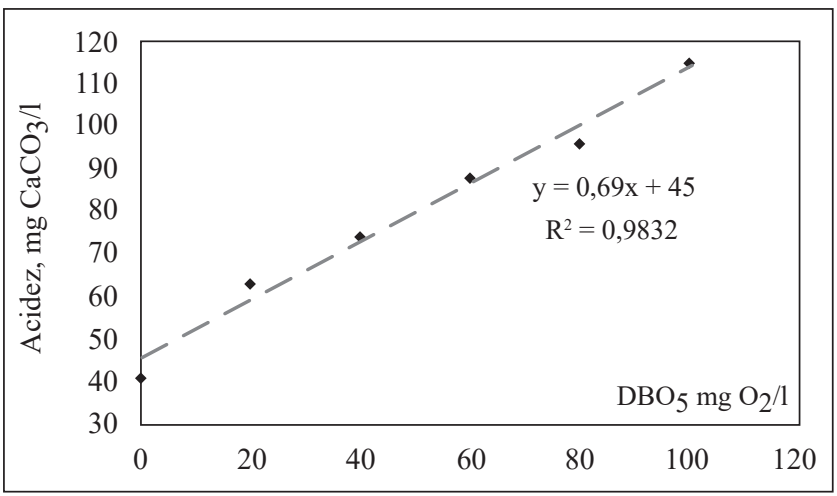

Figura 1. Acidez vs DBO en patrones de glucosa-glutámico, rango bajo

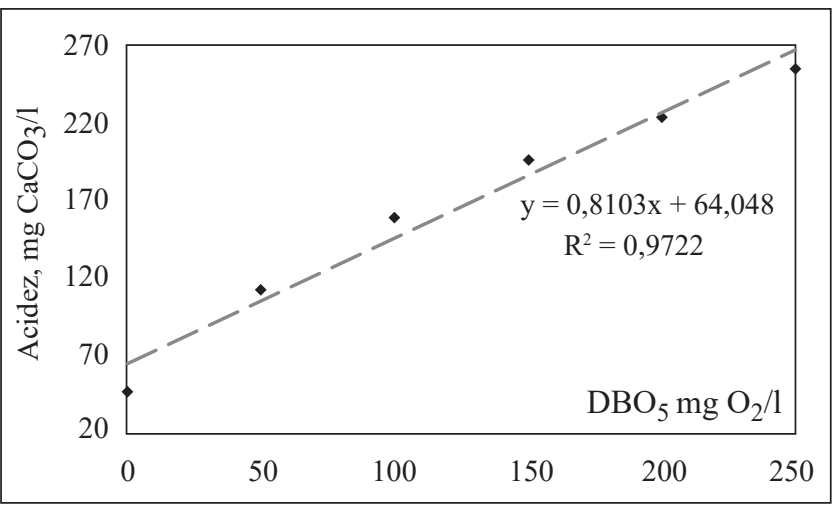

Figura 2. Acidez vs DBO en patrones de glucosa-glutámico, rango medio

experimentales obtenidos en la medición de la $\mathrm{DBO}$, por el método estándar de incubación a cinco días, mientras que en los dos últimos, se presentan solo las relaciones entre las variables estudiadas.

Ensayo 1: acidez vs DBO en agua residual doméstica. La muestra de agua residual doméstica, tratada según lo indicado anteriormente, se dividió en dos porciones. Con una de ellas se midió la $\mathrm{DBO}_{5}$, por el método estándar de incubación a cinco días, tabla $1, y$, con la otra, se realizaron las pruebas de acidez, antes y después del proceso de incubación, tabla 2.

El valor de DBO obtenido en la tabla 1, $263 \mathrm{mg} \mathrm{O} / 1$, se tomó como valor verdadero para calcular los valores de DBO de la tabla 2, en la cual se comparan los valores de DBO, con los correspondientes valores de acidez, medidos, antes y después del proceso de incubación de las muestras.

Se destacan tres hechos relevantes en la tabla 2. El primero es el alto valor inicial de la acidez en la solución control que, téngase en cuenta, contiene ácido glutámico. El segundo es el valor casi constante de la acidez inicial en las muestras, para cualquier concentración de DBO y, el tercero, un valor creciente de acidez final, que se corresponde con una concentración creciente de DBO. 
Tabla 1. Ensayo 1: resultados $\mathrm{DBO}_{5}$, método estándar

\begin{tabular}{|c|c|c|c|c|c|}
\hline Blanco/Control/Muestras & $\begin{array}{l}\text { Factor de } \\
\text { dilución }\end{array}$ & $\begin{array}{c}\mathrm{ml} \mathrm{Na}_{2} \mathrm{~S}_{2} \mathrm{O}_{3} \\
0,025 \mathrm{~N}\end{array}$ & $\begin{array}{l}\mathrm{O}_{2} \text { disuelto } \\
\mathrm{mg} \mathrm{O}_{2} / \mathrm{l}\end{array}$ & $\begin{array}{c}\mathrm{DBO}_{5} \\
\mathrm{mg} \mathrm{O}_{2} / 1\end{array}$ & Observaciones \\
\hline Blanco R-1 & --- & 3,34 & \multirow[t]{3}{*}{6,5} & \multirow[t]{3}{*}{---- } & \multirow[t]{3}{*}{---} \\
\hline Blanco R-2 & --- & 3,25 & & & \\
\hline Blanco R-3 & --- & 3,16 & & & \\
\hline Control R-1 & 50 & 0,92 & \multirow[t]{3}{*}{1,96} & \multirow[t]{3}{*}{227} & \multirow{3}{*}{$\begin{array}{l}\text { Valor consecuente con las cantidades } \\
\text { de glucosa y glutámico experimentales }\end{array}$} \\
\hline Control R-2 & 50 & 1,02 & & & \\
\hline Control R-3 & 50 & 1,01 & & & \\
\hline $\mathrm{M}_{\text {DILUIDA }} 8: 1000 \mathrm{R}-1$ & 125 & 2,26 & \multirow[t]{3}{*}{4,54} & \multirow[t]{3}{*}{245} & \multirow{9}{*}{$\begin{array}{l}\text { Promediando los dos últimos valores, } \\
\text { se obtiene que la DBO de la muestra de } \\
\text { trabajo, en este ensayo, es: DBO: } 263 \\
\mathrm{mg} \mathrm{O}_{2} / \mathrm{L}\end{array}$} \\
\hline $\mathrm{M}_{\text {DILUIDA }} 8: 1000 \mathrm{R}-2$ & 125 & 2,22 & & & \\
\hline $\mathrm{M}_{\text {DILUIDA }} 8: 1000 \mathrm{R}-3$ & 125 & 2,32 & & & \\
\hline $\mathrm{M}_{\text {DILUIDA }} 10: 1000 \mathrm{R}-1$ & 100 & 2,01 & \multirow[t]{3}{*}{3,9} & \multirow[t]{3}{*}{260} & \\
\hline $\mathrm{M}_{\text {DILUIDA }} 10: 1000 \mathrm{R}-2$ & 100 & 1,92 & & & \\
\hline $\mathrm{M}_{\text {DILUIDA }} 10: 1000 \mathrm{R}-3$ & 100 & 1,92 & & & \\
\hline $\mathrm{M}_{\text {DILUIDA }} 12: 1000 \mathrm{R}-1$ & 83,33 & 1,66 & \multirow[t]{3}{*}{3,3} & \multirow[t]{3}{*}{266} & \\
\hline $\mathrm{M}_{\text {DILUIDA }} 12: 1000 \mathrm{R}-2$ & 83,33 & 1,62 & & & \\
\hline $\mathrm{M}_{\text {DILUIDA }} 12: 1000 \mathrm{R}-3$ & 83,33 & 1,68 & & & \\
\hline
\end{tabular}

R-1, R-2 y R-3: réplicas 1,2 y 3

$\mathrm{M}_{\text {DILUIDA }}$ 8:1000: muestra diluida 8 a $1000 \mathrm{ml}$, con agua de dilución

Tabla 2. Ensayo 1: acidez vs DBO en agua residual doméstica

\begin{tabular}{|c|c|c|c|c|c|}
\hline \multirow[t]{2}{*}{ Blanco/Control/Muestras } & \multirow{2}{*}{$\begin{array}{c}\text { Factor de } \\
\text { dilución }\end{array}$} & \multirow{2}{*}{$\begin{array}{c}\mathrm{DBO}_{\mathrm{REAL}} \\
\mathrm{mg} \mathrm{O}_{2} / \mathrm{L}\end{array}$} & \multicolumn{3}{|c|}{ Acidez, mg $\mathrm{CaCO}_{3} / \mathrm{l}$} \\
\hline & & & Acidez $_{\text {INICIAL }}$ & Acidez $_{\text {FINAL }}$ & $\Delta_{\text {ACIDEZ }}$ \\
\hline Blanco & ---- & 0 & 13 & 18 & 5 \\
\hline Control & ---- & 227 & 66 & 165 & 99 \\
\hline MT 30:500 R-1 & \multirow[b]{2}{*}{16,7} & 16 & \multirow{2}{*}{12} & \multirow{2}{*}{25} & \multirow[t]{2}{*}{13} \\
\hline MT 30:500 R-2 & & & & & \\
\hline MT 60:500 R-1 & \multirow[b]{2}{*}{8,3} & 32 & \multirow{2}{*}{13} & \multirow{2}{*}{40} & \multirow[t]{2}{*}{27} \\
\hline MT 60:500 R-2 & & & & & \\
\hline MT 90:500 R-1 & \multirow[b]{2}{*}{5,6} & 47 & \multirow{2}{*}{14} & \multirow{2}{*}{47} & \multirow[t]{2}{*}{33} \\
\hline MT 90:500 R-2 & & & & & \\
\hline MT 120:500 R-1 & \multirow{3}{*}{$\begin{array}{l}4,2 \\
3,3\end{array}$} & 63 & \multirow{2}{*}{14} & \multirow{2}{*}{62} & \multirow[t]{2}{*}{48} \\
\hline MT 120:500 R-2 & & & & & \\
\hline MT 150:500 R-1 & & 79 & 14 & 68 & 54 \\
\hline
\end{tabular}

$\mathrm{R}-1, \mathrm{R}-2$ y $\mathrm{R}-3$ : réplicas 1,2 y 3

MT: muestra de trabajo. Buffer aplicado $6 \mathrm{ml}$ por cada litro de muestra, blanco o control

En la figura 3 se grafican los resultados de acidez vs DBO, correspondientes a la tabla 2. En ella se observa una relación lineal entre la DBO de las muestras y el valor de la acidez final, relación que se caracteriza en este ensayo, por un coeficiente de correlación lineal superior al $98 \%$. Obsérvese que al graficar el delta de acidez (acidez final menos acidez inicial) contra la DBO de las muestras, la linealidad se mantiene. Este hecho sugiere que es posible medir la DBO de una muestra, de agua residual doméstica, en función del valor de su acidez final, esto es, que no es necesario medir la acidez inicial, por cuanto ésta corresponde a un valor prácticamente constante, que no depende de su valor de DBO, sino, más bien, de su naturaleza ácida o básica.
Nótese también que las rectas que representan los datos de acidez y delta de acidez son prácticamente paralelas entre sí y que la recta que representa los valores de acidez inicial en las muestras, es prácticamente paralela al eje X.

Los resultados de este ensayo indican claramente, que análogamente a cuando se trabaja con patrones de glucosaglutámico, existe una relación lineal inequívoca, entre la DBO de una muestra de agua residual doméstica y la acidez generada como consecuencia de la metabolización de la materia orgánica contenida en ella.

Estos resultados son importantes, por cuanto medir la DBO en función de la acidez, simplifica el método estándar de incubación a cinco días: reduce o elimina por completo 
la necesidad de diluir las muestras y reduce la operatividad y las áreas de trabajo, lo cual, redunda en el mejoramiento de la reproducibilidad de las mediciones. Además, el uso de botellas comerciales para realizar las pruebas de DBO, reduce substancialmente el costo de los equipos implícitos en la medición y abre una puerta para el diseño de nuevos equipos, más simples y económicos.

Cuando se repitieron estos ensayos, con muestras de agua residual doméstica, proveniente de la misma fuente, se observaron relaciones semejantes entre las variables estudiadas. Sin embargo, el valor cambiante de DBO, del agua que ingresa a la planta cada día, dificulta establecer relaciones directas absolutas. Por lo tanto, es válido afirmar que existe una relación lineal entre la DBO de una muestra de agua residual y la acidez que se genera durante su incubación, pero la relación exacta y cuantitativa requiere de mediciones seriales de largo plazo.

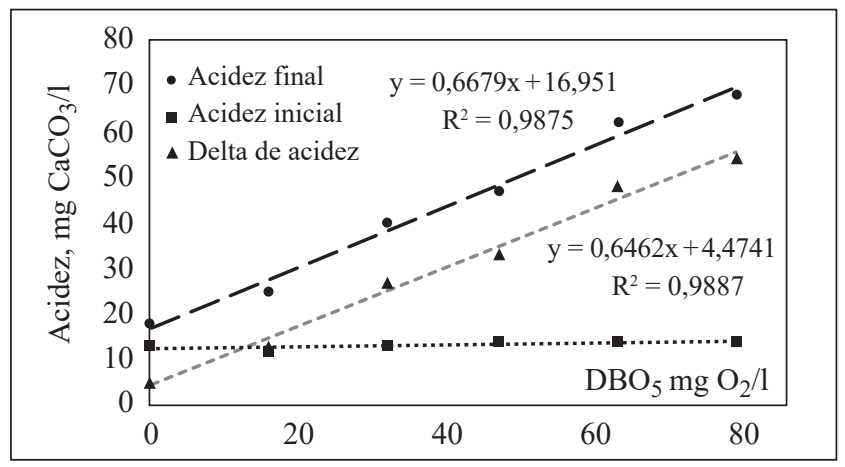

Figura 3. Ensayo 1: acidez vs DBO en muestras de agua residual doméstica
Ensayo 2: acidez vs DBO en agua residual doméstica. Las tablas 3 y 4 muestran los resultados obtenidos para un ensayo semejante al anterior, en el que se mantuvieron las mismas condiciones experimentales, pero se trabajó con una muestra diferente, proveniente de la misma fuente. Análogamente al primer ensayo, la tabla 3 muestra los datos obtenidos en la medición de la DBO, por el método estándar de incubación a cinco días y la tabla 4 , los valores de acidez inicial y final, obtenidos para diluciones graduales de la muestra de trabajo.

El valor de DBO obtenido en la tabla 3, se utilizó para calcular los valores de DBO de las muestras diluidas, que se muestran en la tabla 4.

Nótese cómo, los mismos hechos relevantes observados en la tabla 2, se presentan también en la tabla 4: Un alto valor inicial de acidez en la solución control, un valor más o menos constante de acidez inicial en las muestras, y un valor creciente de acidez final, que se corresponde con una concentración creciente de DBO.

En la figura 4 se grafican los resultados de acidez vs $\mathrm{DBO}$, correspondientes a la tabla 4 . Obsérvese que aunque cambian las pendientes, - de 0,66 para la acidez final en el primer ensayo, a 0,59 para la acidez final en el segundola linealidad se mantiene y los coeficientes de correlación lineal, escasamente disminuyen en 1\%. Para efectos prácticos, el comportamiento de la relación existente entre las variables estudiadas, es el mismo, pues las diferencias entre uno y otro ensayo, caen dentro de las variaciones del error experimental, particularmente si se tiene en cuenta, que en el método estándar de incubación a cinco días, las diferencias aceptadas pueden llegar hasta el 25\%, (Eaton, et al., 2005).

Tabla 3. Ensayo 2: resultados $\mathrm{DBO}_{5}$, método estándar

\begin{tabular}{|c|c|c|c|c|c|}
\hline Blanco/Control/Muestras & $\begin{array}{l}\text { Factor de } \\
\text { dilución }\end{array}$ & $\begin{array}{c}\mathrm{ml} \mathrm{Na} \mathrm{Na}_{2} \mathrm{O}_{3} \\
\mathbf{0 , 0 2 5} \mathrm{N}\end{array}$ & $\begin{array}{l}\mathrm{O}_{2} \text { disuelto } \\
\mathrm{mg} \mathrm{O}_{2} / \mathrm{l}\end{array}$ & $\begin{array}{c}\mathrm{DBO}_{5} \\
\mathrm{mg} \mathrm{O}_{2} / 1\end{array}$ & Observaciones \\
\hline Blanco R-1 & --- & 3,13 & \multirow[t]{3}{*}{6,17} & \multirow[t]{3}{*}{---- } & \multirow[t]{3}{*}{--- } \\
\hline Blanco R-2 & --- & 3,04 & & & \\
\hline Blanco R-3 & --- & 3,09 & & & \\
\hline Control R-1 & 50 & 0,98 & \multirow[t]{3}{*}{1,94} & \multirow[t]{3}{*}{212} & \multirow{3}{*}{$\begin{array}{l}\text { Valor esperado para las cantidades } \\
\text { de glucosa y glutámico pesadas: } 205\end{array}$} \\
\hline Control R-2 & 50 & 0,95 & & & \\
\hline Control R-3 & 50 & 0,98 & & & \\
\hline $\mathrm{M}_{\text {DILUIDA }} 8: 1000 \mathrm{R}-1$ & 125 & 2,07 & \multirow[t]{3}{*}{4,1} & \multirow[t]{3}{*}{259} & \multirow{9}{*}{$\begin{array}{l}\text { Promediando los tres valores, se } \\
\text { obtiene que la DBO de la muestra } \\
\text { de trabajo es: } 249 \mathrm{mg} \mathrm{O}_{2} / \mathrm{L}\end{array}$} \\
\hline $\mathrm{M}_{\text {DILUIDA }} 8: 1000 \mathrm{R}-2$ & 125 & 2,01 & & & \\
\hline $\mathrm{M}_{\text {DILUIDA }} 8: 1000 \mathrm{R}-3$ & 125 & 2,07 & & & \\
\hline $\mathrm{M}_{\text {DILUIDA }} 10: 1000 \mathrm{R}-1$ & 100 & 1,90 & \multirow[t]{3}{*}{3,7} & \multirow[t]{3}{*}{247} & \\
\hline $\mathrm{M}_{\text {DILUIDA }} 10: 1000 \mathrm{R}-2$ & 100 & 1,81 & & & \\
\hline $\mathrm{M}_{\text {DILUIDA }} 10: 1000 \mathrm{R}-3$ & 100 & 1,83 & & & \\
\hline $\mathrm{M}_{\text {DILUIDA }} 12: 1000 \mathrm{R}-1$ & 83,3 & 1,64 & \multirow[t]{3}{*}{3,29} & \multirow[t]{3}{*}{240} & \\
\hline $\mathrm{M}_{\text {DILUIDA }} 12: 1000 \mathrm{R}-2$ & 83,3 & 1,65 & & & \\
\hline $\mathrm{M}_{\text {DILUIDA }} 12: 1000 \mathrm{R}-3$ & 83,3 & 1,64 & & & \\
\hline
\end{tabular}

R-1, R-2 y R-3: réplicas 1,2 y 3

$\mathrm{M}_{\text {DILUIDA }}$ 8:1000: muestra diluida 8 a $1000 \mathrm{ml}$, con agua de dilución 
Tabla 4. Ensayo 2: acidez vs DBO en agua residual doméstica

\begin{tabular}{|c|c|c|c|c|c|}
\hline \multirow[t]{2}{*}{ Blanco/Control/Muestras } & \multirow{2}{*}{$\begin{array}{l}\text { Factor de } \\
\text { dilución }\end{array}$} & \multirow{2}{*}{$\begin{array}{c}\text { DBO }_{\text {EXPERIMENTAL }} \\
\mathrm{mg} \mathrm{O}_{2} / \mathbf{l}\end{array}$} & \multicolumn{3}{|c|}{ Acidez, $\mathrm{mg} \mathrm{CaCO}_{3} / \mathbf{l}$} \\
\hline & & & Acidez $_{\text {INICIAL }}$ & Acidez $_{\text {FINAL }}$ & $\Delta_{\text {ACIDEZ }}$ \\
\hline Blanco & --- & & 7 & 10 & 3 \\
\hline Control & 50,0 & 212 & 73 & 131 & 58 \\
\hline MT 30:500 & 16,7 & 15 & 8 & 25 & 17 \\
\hline MT 60:500 & 8,3 & 30 & 8 & 35 & 27 \\
\hline MT 90:500 & 5,6 & 45 & 9 & 44 & 35 \\
\hline MT 120:500 & 4,2 & 60 & 10 & 54 & 44 \\
\hline MT 150:500 & 3,3 & 75 & 12 & 66 & 54 \\
\hline MT 180:500 & 2,8 & 90 & 11 & 70 & 59 \\
\hline MT 210:500 & 2,4 & 105 & 12 & 78 & 66 \\
\hline MT 240:500 & 2,1 & 119 & 12 & 80 & 68 \\
\hline
\end{tabular}

R-1, R-2 y R-3: réplicas 1,2 y 3

MT: muestra de trabajo.

Buffer aplicado, $6 \mathrm{ml}$ por cada litro de muestra, blanco o control.

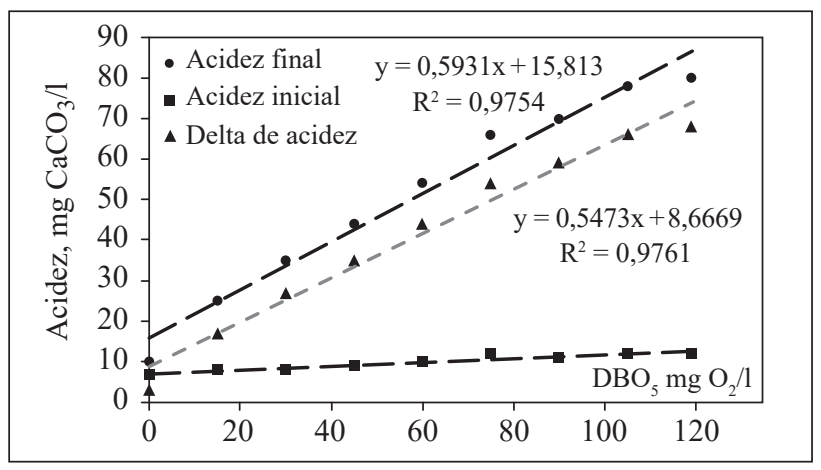

Figura 4. Ensayo 2: acidez vs DBO en muestras de agua residual doméstica

Finalmente, la correspondencia entre la DBO de la muestra y la acidez producida durante la incubación, se da tanto para la acidez final como para el delta de acidez, lo cual corrobora la posibilidad de simplificar la medición de DBO, mediante una sola medición de la acidez, al final de la prueba.

Este hecho se puede comprobar calculando con cualquiera de las ecuaciones del ensayo 1,-acidez o delta de acidez- los valores de DBO en el ensayo 2, a partir de la acidez final o del delta de acidez. Mientras se trabaje dentro del rango de concentración coincidente - de 20 a $80 \mathrm{mg} \mathrm{O} /$ 1- las desviaciones obtenidas son inferiores al $10 \% \mathrm{y}$, lo que es más importante, siempre inferiores al $25 \%$, que es la desviación máxima aceptada para el método estándar.

A modo de ejemplo, si mediante la ecuación $\mathrm{Y}=$ $0,6679 X+16,951$, obtenida en el ensayo 1 , se calcula la DBO de la muestra correspondiente a la acidez final de 54, obtenida en el ensayo 2, se llega al siguiente resultado: DBO experimental $60 \mathrm{mg} \mathrm{O}_{2} / 1$ y DBO calculado, $55,5 \mathrm{mg} \mathrm{O}_{2} / 1$ '.

Ensayos 3 y 4: acidez vs DBO en agua residual doméstica. En estos dos últimos ensayos, se realiza un procedimiento experimental semejante al descrito anteriormente, la única diferencia con respecto a los anteriores, es la concentración del buffer, que pasó, de $6,0 \mathrm{ml}$ por litro, en los primeros ensayos a $4,0 \mathrm{ml}$ por litro, para blancos, patrones y muestras, en estos últimos dos ensayos.

En general, en este estudio se realizaron ensayos variando la cantidad de buffer, entre 2 y $5 \mathrm{ml}$, por cada $500 \mathrm{ml} \mathrm{de}$ blanco, muestra o patrón. Sin embargo, para las muestras de agua residual estudiadas, cuyos rangos de DBO variaron aproximadamente entre 20 y $150 \mathrm{mg} \mathrm{O}_{2} / 1$, los mejores resultados se obtuvieron con dosificaciones de 2-3 $\mathrm{ml}$ de buffer, por cada $500 \mathrm{ml}$ de blanco, muestra o patrón.

La tabla 5 y la figura 5 , corresponden al ensayo 3 , en el cual, la DBO de la muestra, medida por el método estándar de incubación a cinco días, dio como resultado el valor de $218 \mathrm{mg} \mathrm{O}_{2} / \mathrm{l}$. Con este resultado se calcularon los valores de DBO que aparecen registrados en la tabla 5.

Obsérvese que el resultado es muy semejante al obtenido en los ensayos 1 y 2 y que la única diferencia consiste en la reducción de los deltas de acidez. Así, por ejemplo, en éste ensayo, un delta de acidez de 54, se corresponde con una DBO de $122 \mathrm{mg} \mathrm{O}_{2} / 1$, mientras que en los ensayos 1 y 2 , éste delta se correspondía con una DBO de aproximadamente $77 \mathrm{mg} \mathrm{O} / 1$.

La figura 5 muestra claramente que las tendencias se mantienen, tanto para la acidez final como para el delta de acidez. El paralelismo entre las rectas de interés es prácticamente idéntico y el valor de la acidez inicial de las muestras también. Por otra parte, los coeficientes de correlación lineal, escasamente cambian.

De cualquier modo, se debe tener presente, que si bien la reducción de la cantidad de buffer aplicado a los blancos, muestras y patrones, permite que los incrementos de acidez se relacionen cada vez más estrechamente con el metabolismo de la materia orgánica contenida en la muestra, una cantidad de buffer demasiado ajustada a la cantidad de acidez generada por el metabolismo, reduce también la posibilidad de atrapar 
Tabla 5. Ensayo 3: acidez vs DBO en agua residual doméstica

\begin{tabular}{|c|c|c|c|c|c|}
\hline \multirow[t]{2}{*}{ Blanco/Control/Muestras } & \multirow[t]{2}{*}{ Factor de dilución } & \multirow{2}{*}{$\begin{array}{c}\text { DBO }_{\text {EXPERIMENTAL }} \\
\mathrm{mg} \mathrm{O}_{2} / \mathrm{l}\end{array}$} & \multicolumn{3}{|c|}{ Acidez, $\mathrm{mg} \mathrm{CaCO}_{3} / \mathrm{l}$} \\
\hline & & & Acidez $_{\text {INICIAL }}$ & Acidez $_{\text {FINAL }}$ & $\Delta_{\text {ACIDEZ }}$ \\
\hline Blanco & --- & & 13 & 17 & 3 \\
\hline Control & 50,0 & 212 & 60 & 116 & 56 \\
\hline MT 40:500 & 12,5 & 17 & 14 & 27 & 13 \\
\hline MT 80:500 & 6,25 & 35 & 14 & 40 & 26 \\
\hline MT 120:500 & 4,17 & 52 & 14 & 46 & 32 \\
\hline MT 160:500 & 3,13 & 70 & 14 & 50 & 36 \\
\hline MT 200:500 & 2,5 & 87 & 14 & 56 & 42 \\
\hline MT 240:500 & 2,08 & 105 & 14 & 61 & 47 \\
\hline MT 280:500 & 1,79 & 122 & 14 & 68 & 54 \\
\hline MT 320:500 & 1,56 & 139 & 14 & 70 & 56 \\
\hline
\end{tabular}

MT: muestra de trabajo

MT 40:500: muestra de trabajo diluida 40 a 500, con agua de dilución

Buffer aplicado, $4 \mathrm{ml}$ por cada litro de muestra, blanco o control

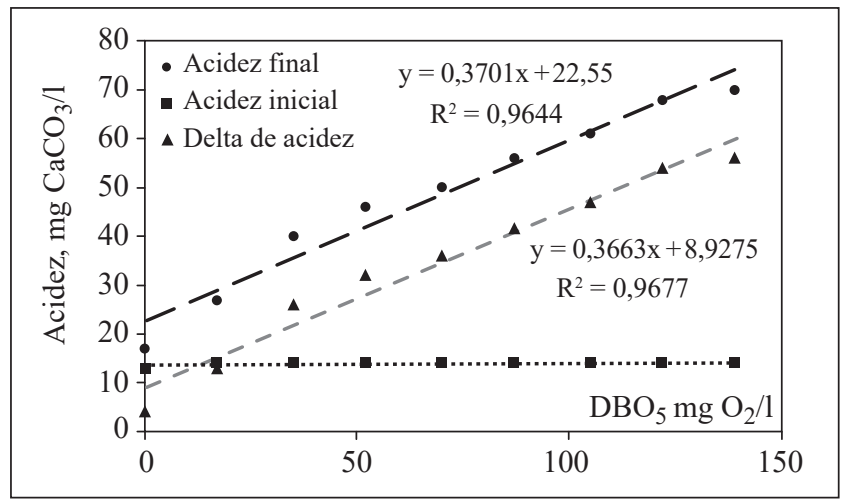

Figura 5. Ensayo 3: acidez vs DBO en muestras de agua residual doméstica

el bióxido de carbono en la fase acuosa. Por esta razón, no es conveniente utilizar la misma concentración de buffer, que se utiliza en el método estándar de incubación a cinco días.

En la tabla 6 y la figura 6 , se muestran los resultados correspondientes al ensayo 4. En este ensayo la DBO medida por el método de incubación a cinco días, dio como resultado, el valor de $203 \mathrm{mg} \mathrm{O} / 1$. Con este valor se calcularon las DBO que aparecen registradas en la tabla 6. Obsérvese la similitud gráfica y tabulada obtenida en estos dos ensayos, ambos realizados con la misma cantidad de buffer concentrado.

Al igual que en los dos primeros ensayos, se pueden calcular, con las ecuaciones del ensayo 3, los valores de DBO del ensayo 4 y viceversa, con discrepancias inferiores al $10 \%$. La concordancia entre los valores de DBO calculados y los experimentales, reflejan las bondades de una posible medición de DBO, en función de la acidez generada durante la incubación de las muestras.

Por último, vale la pena tener presente que el propósito de este estudio era averiguar mediante experimentación, si existía o no, una relación entre las variables DBO y acidez generada durante la incubación y, adicionalmente, determinar el tipo de relación existente, entre dichas variables, en caso de encontrarse. Es por esto que durante la experimentación se determina primero la DBO de la muestra de trabajo, por el método estándar. Conocer ese valor, nos permite asociar la acidez producida, con un valor fiable de DBO.

Sin embargo, puesto que cada ensayo se realiza con una muestra diferente, no es posible obtener aún, una relación precisa entre la $\mathrm{DBO}$ expresada en $\mathrm{mg} \mathrm{O}_{2} / 1$ y la DBO expresada en $\mathrm{mg} \mathrm{CaCO}_{3} / \mathrm{l}$. Ese es el objetivo de la segunda fase de este estudio, que se realiza actualmente con soluciones patrón de glucosa-glutámico y que se proyectará también a muestras reales de agua residual doméstica.

\section{Conclusiones}

La acidez producida durante el metabolismo aerobio de la materia orgánica presente en una muestra de agua residual doméstica, es directamente proporcional a su carga orgánica o DBO.

La acidez producida durante la metabolización de la materia orgánica contenida en una muestra de agua residual doméstica, se puede atrapar dentro de la fase acuosa, mediante la adición de un buffer concentrado y cuantificar posteriormente, por titulación con una base fuerte.

La DBO de las aguas residuales domésticas, puede medirse por cuantificación de la acidez producida durante el metabolismo de la materia orgánica contenida, con ventajas comparativas, en relación con el método estándar de incubación a cinco días.

La medición de la DBO, de las aguas residuales domésticas, en función de la acidez producida durante la incubación de las muestras, reduce o elimina la necesidad de diluir las muestras y simplifica la operatividad de la medición, en relación con el método estándar de incubación a cinco días. 
Tabla 6. Ensayo 4: acidez vs DBO en agua residual doméstica

\begin{tabular}{|c|c|c|c|c|c|}
\hline \multirow[t]{2}{*}{ Blanco/Control/Muestras } & \multirow[t]{2}{*}{ Factor de dilución } & \multirow{2}{*}{$\begin{array}{c}\text { DBO }_{\text {EXPERIMENTAL }} \\
\mathrm{mg} \mathrm{O}_{2} / \mathbf{l}\end{array}$} & \multicolumn{3}{|c|}{ Acidez, mg CaCO$/ 1$} \\
\hline & & & Acidez $_{\text {INICIAL }}$ & Acidez $_{\text {FINAL }}$ & $\Delta_{\text {ACIDEZ }}$ \\
\hline Blanco & --- & & 15 & 18 & 3 \\
\hline Control & 50,0 & 222 & 65 & 128 & 63 \\
\hline MT 50:500 & 10 & 20 & 16 & 35 & 19 \\
\hline MT 100:500 & 5 & 41 & 16 & 41 & 25 \\
\hline MT 150:500 & 3,3 & 61 & 16 & 51 & 35 \\
\hline MT 200:500 & 2,5 & 81 & 17 & 60 & 43 \\
\hline MT 250:500 & 2,0 & 101 & 17 & 66 & 49 \\
\hline MT 300:500 & 1,7 & 122 & 17 & 71 & 54 \\
\hline MT 350:500 & 1,4 & 142 & 17 & 80 & 63 \\
\hline MT 400:500 & 1,25 & 162 & 17 & 85 & 68 \\
\hline
\end{tabular}

MT: muestra de trabajo

MT 50:500: muestra de trabajo diluida 50 a 500, con agua de dilución

Buffer aplicado, $4 \mathrm{ml}$ por cada litro de muestra, blanco o control

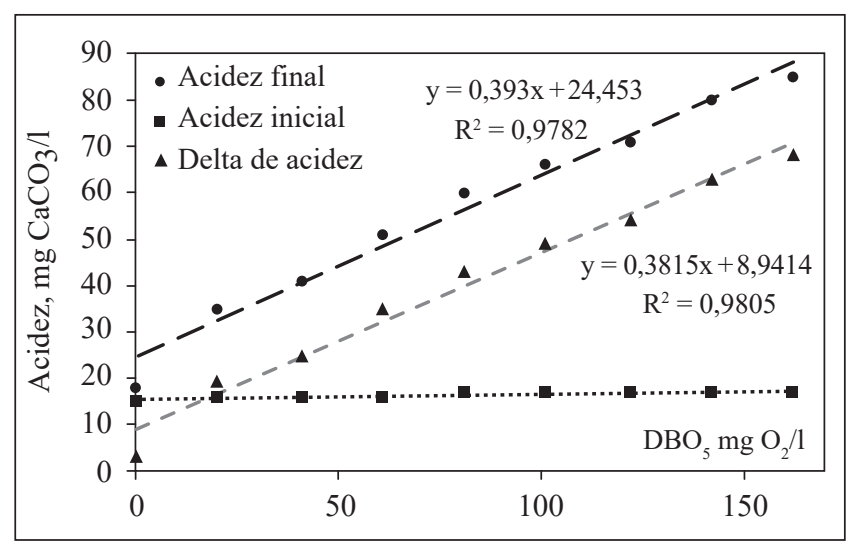

Figura 6. Ensayo 4: acidez vs DBO en muestras de agua residual doméstica

\section{Agradecimientos}

El presente trabajo fue realizado dentro del proyecto 'Desarrollo de metodologías alternas para la medición de DBO (Demanda Biológica de Oxígeno)', que se ejecuta actualmente en el Laboratorio de Aguas, de la Facultad del Medio Ambiente y Recursos Naturales, de la Universidad Distrital Francisco José de Caldas. Los resultados específicos corresponden al avance del proyecto, durante los años 2011 a 2013. Se reconoce y agradece a la Institución por el acceso a las instalaciones y por el suministro de los reactivos utilizados en el desarrollo de la investigación.

Se reconoce y agradece también, la Colaboración de la Empresa de Acueducto y Alcantarillado de Bogotá y específicamente al Ingeniero Eduardo López, por su apoyo en la obtención de las muestras y en la coordinación de los resultados.

\section{Conflicto de intereses}

Los autores declaran que no existen conflictos de interés de ninguna índole.

\section{Referencias}

Calderon, F. (2007). [en línea], http://www.drcalderonlabs.com/ Metodos/Analisis_De_Aguas/Determinacion_DBO5_Metodo_ Respirometrico.html [consulta: 11 de mayo de 2016].

Dogan, E; Sengorur, B; Koklu, R. (2009). Modeling biological oxygen demand of the Melen River in Turkey using an artificial neural network technique. J Environment Manag 90: 1229-1235.

Eaton, A; Clesceri, L; Rice,E; Greenberg, A. (2005). Standard Methods For the examination of water \& wastewater. 21 st Edition, Centennial Edition, USA, pp. 4-28, 5-2, 4-33, 4-34, 5-2, 5-7, 5-10, 5-13.

Jouanneau, S.; Recoules, L.; Durand, M.J.; Boukabache, A.; Picot, V. Primault, Y; et al. (2014). "Methods for assessing biochemical oxygen demand (BOD): A review". Water Research. 49: 62- 82. Recuperado de http://ac.elscdn.com. bdigital.udistrital.edu.co:8080/S0043135413008920/1-s2.0S0043135413008920-main.pdf? tid=fbfa86b2-4831-11e6b870-00000aacb35e\&acdnat $=1468329200 \_087 a 5 b 1298437$ 1298054eca4b392f3a5 (Consultado el 11 de mayo de 2016).

Li, Y; Suna, J; Wanga, J; Biana, C; Tonga, J; Li, Y; et al. (2016). A single-layer structured microbial sensor for fast detection of biochemical oxygen demand. Biochem Engineer J. 112: 219-225.

Liu, C; Li, Z; Jiang, D; Jia, J; Zhang, Y; Chai, Y; et al. (2016). Demonstration study of biofilm reactor based rapid biochemical oxygen demand determination of surface water. Sensing and Bio-Sensing Res 8: 8-13.

Wilde, F.D; Sandstrom, M.W; Skrobialowski, S.C. (2014). Selection of equipment for water sampling (ver. 3.1): U.S. Geological Survey Techniques of Water-Resources Investigations, book 9, chap. A2, 78. [en línea], http:// water.usgs.gov/owq/FieldManual/Chapter6/table6.2_6.pdf$>$ [consulta: 11 de mayo de 2016] 